\title{
TINGKAT PENGETAHUAN SISWA TENTANG FISIOTERAPI DI SMK NEGERI 2 SIBOLGA KOTA SIBOLGA
}

\author{
Sulaiman $^{1)}$, Maryaningsih' ${ }^{2)}$, Anggriani $^{3)}$ \\ STIKES Siti Hajar ${ }^{1)}$ \\ STIKES Siti Hajar ${ }^{2)}$ \\ STIKES Siti Hajar ${ }^{3)}$
}

\begin{abstract}
ABSTRAK
Fisioterapi di Sumatera Utara sampai saat ini masih belum dikenal luas oleh masyarakat. Salah satu dampak dari ketidaktahuan siswa tersebut adalah sebagian besar jurusan fisioterapi diperguruan tinggi di Sumatera Utara Khusunya tidak banyak diminati oleh siswa. Dampak lainnya banyak terjadi kasus fisioterapi yang tidak dapat diberi pelayanan dengan baik disebabkan tenaga fisioterapi yang masih kurang. Penyuluhuan ini dilakukan di SMK Negeri 2 Sibolga Kota Sibolga terhadap siswa kelas XII sebanyak 100 siswa. Metode pelaksanaannya adalah dengan memberikan penyuluhan atau sosialisasi kepada siswa, diberikan kuisioner sebelum dan sesudah sosialisasi kepada siswa. Hasilnya banyak siswa yang belum paham tentang fisioterapi, dan prospek di masa yang akan datang. Namun setelah di beri sosialisasi, siswa dapat mengerti dengan baik. Kesimpulan. Sebelum dilakukan sosialisasi, sebagian besar siswa SMK Negeri 2 Kota Sibolga masih belum tahu tentang fisioterapi. Jurusan fisioterapi masih belum menjanjikan bisa mendapat langsung pekerjaan. Semua siswa pada dasarnya sama ingin melanjutkan kuliah yang bias langsung mendapatkan pekerjaan sesuai dengan harapan orang tua
\end{abstract}

Kata kunci: Fisoterapi, Pengetahuan Siswa

\begin{abstract}
Physiotherapy in North Sumatra is still not widely known by the community Maksimum tiga . One of the impact of this student's ignorance is that most of the physiotherapy majors in higher education in North Sumatra are not particularly popular with students. Another impact is that there are many cases of physiotherapy who cannot be given good service due to lack of physiotherapy. This extension was conducted at Sibolga State Vocational High School 2, Sibolga City for 100 students in class XII. The method of implementation is to provide counseling or socialization to students, questionnaire given before and after socialization to students. The result is that many students do not understand physiotherapy, and prospects in the future. But after being given socialization, students can understand well. Conclusion. Before the socialization, the majority of students at SMK Negeri 2 Kota Sibolga still did not know about physiotherapy. The physiotherapy department is still not promising to get a job directly. All students are basically the same as they want to continue their studies which can immediately get a job in accordance with the expectations of parents.
\end{abstract}

Kata kunci: Physiotherapy, Student Knowledge

\section{PENDAHULUAN}

Fisioterapi di Indonesia masih dikatakan asing dan belum dimengerti oleh masyarakat, khususnya pada kalangan pelajar SMA sederajat. Mereka lebih mengertii keperawatan kesehatan gigi, kedokteran dan lain sebagainya. Padahal fisioterapi merupakan bagian dari kesehatan.
Menurut Departem Kesehatan Republik Indonesia, fisioterapi adalah bentuk pelayanan kesehatan yang ditujukan kepada individu dan/atau kelompok untuk mengembangkan, memelihara dan memulihkan gerak dan fungsi tubuh sepanjang rentang kehidupan dengan menggunakan penanganan secara manual, peningkatan gerak, peralatan (physics, elektroterapeutis 
dan mekanis) pelatihan fungsi, dan komunikasi (Kemenkes RI, 2017) .

Sedangan menurut WCPT tahun 1999, fisioterapi adalah suatu ilmu atau kiat untuk melakukan suatu pengobatan dengan memanfatkan khasiat alam seperti cahaya, air, listrik, latihan-latihan dan manual . Begitu luasnya cakupan fisioterapi dan luasnya lapangan pekerjaan membuat fisioterapi sangat dibutuhkan di Indonesia. Kasus yang dapat ditangani oleh fisioterapi cukup banyak, mulai dari anak- anak sampai dengan lanjut usia.

Pada lanjut usia salah satu gangguang kesehatan yang terjadi adalah keseimbangan. Hal ini seperti yang terjadi pada lanjut usia di desa Sukaraya Kecamatan Pancur Batu rata-rata mengalami gangguan keseimbangan (Sulaiman \& Anggriani, 2018). Selain itu fisioterapi juga efektif untuk menangani kasus stroke. Pengabdian yang dilakukan sebelumnya mengatakan bahwa pemberian sinar infra red untuk lansia yang mengalami gejala stroke dan gangguan fisik lainnya sangat efektif untuk memulihkan gangguan stroke pada lansia (SULAIMAN, \& ANGGRIANI, 2017).

SMK Negeri 2 Kota Sibolga Provisnsi Sumatera Utara mempunya siwa laki-laki sebanyak 448 dan perempuan sebanyak 470 siswa. Rata-rata setelah lulus mereka akan melanjutkan ke perguruan tinggi dan setelah lulus kuliah langsung ingin dapat pekerjaan. Namun mereka bingung untuk menentukan jurusan yang akan dipilih, dikarenakan belum tahu jurusan apa yang berpeluang mendapat pekerjaan dengan mudah.

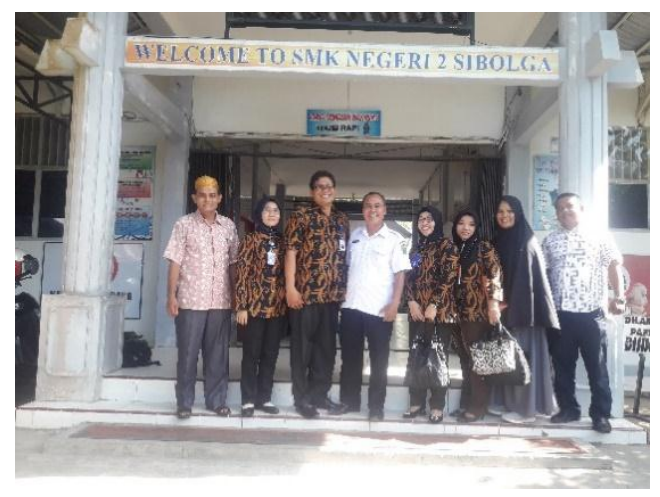

Gambar 1. Foto Tim Pengabdian dengan Kepala Sekolah, Guru SMKN 2 Sibolga

\section{Permasalahan}

Dari analisis situasi di SMK Negeri 2 Sibolga Kota Sibolga Provinsi Sumatera Utara ditemukan permasalahan sebagi berikut :

1. Para siswa tidak mengetahui apa itu fisioterapi dan ilmu fisioterapi

2. Tidak mngetahui peluang kerja fisioterapi

3. Tidak mengetahui kalau fisioterapi juga ada program pendikakannya mulai dari diploma tiga sampai dengan pasca sarjana.

\section{Permasalahan Prioritas.}

Melihat kompleks dan banyaknya permasalahan yang di hadapi oleh siswa SMKN Negeri 2 Kota Sibolga Provinsi Sumatera Utara terbeut, maka tim pengabdian akan memberikan solusi secara kompleks, diantaranya memberikan informasi ketiga permasalahan tersebut. Untuk mengetahui tingkat keberhasilan pengabdian, pada akhir pemgabdian akan diberikan angket sebagai evaluasi kegiatan.

\section{Target}

Target dalam kegiatan pengabdian ini yang dilakukan di 
SMKN 2 Kota Sibolga Provinsi Sumatera Utara adalah siswa paham dan mengerti tentang fisioterapi dan banyak siswa yang lulus masuk perguruan tinggi jurusan fisioterapi

\section{METODE PELAKSANAAN}

Pada pengabdian ini rancangan pengabdian dilakukan dengan metode penyuluhan dan tanya jawab serta pengisian kuisioner yang dilaksanakan pada tanggal 31 Januari 2019.

Subjek dalam pengabdian ini adalah seluruh siswa SMK Negeri 2 Sibolga yang duduk dikelas XII, namun hanya diambil sebagian siswa saja. Mereka yang berminat untuk melanjutkan kuliah diperguruan tinggi. Subjek yang diambil dalam pengabdian ini sebanyak 100 siswa.

Instrumen dalam pengabdian ini menggunakan kuisioner sebagai angket untuk mengetahui pengetahuan fisioterapi sebelum dan sesudah dilakukan penyuluhan, alat pengeras suara sebagai alat unutk menyampaikan bahan penyuluhan atau sosialisasi.

Prosedur pengumpulan data dilakukan pertama kali dengan meminta izin kepada Kepala Sekolah SMK Negeri 2 Sibolga Bapak Abdul Hamid, setelah mendapat izin tim menentukan jadwal yang tepat unutk melakukan pengabdian. Setelah jadwal pengabdian disepakati oleh kedua belah pihak, pelaksanakan pengabdian dilakukan. Pelaksanaan pengabdian dilakukan di ruangan kelas SMK Negeri 2 dibagi menjadi dua sesi, sebelum dan sesudah kegiatan penyuluhan dilakukan, siswa diberikan kuisioner.
Kemudian data yang didapat dibahas dan dianalisis bersama tim pengabdian. Kemudian hasilnya juga akan di bahas bersama tim pengabdian.

\section{HASIL DAN PEMBAHASAN}

Pada pengabdian di SMK Negeri 2 Sibolga Kota Sibolga Provinsi Sumatera Utara sebelum dilakukan penyuluhan tentang pengetahuan siswa terlebih dahulu siswa mengisi kuisioner dan hasilnya dapat dilihat pada Tabel 1 berikut ini.

Tabel 1. Pengetahuan siswa tentang fisioterapi sebelum penyuluhan

\begin{tabular}{|c|c|c|c|}
\hline Pertanyaan & Frek & $\begin{array}{c}\mathrm{Y} \\
(\%)\end{array}$ & $\begin{array}{c}\mathrm{T} \\
(\%)\end{array}$ \\
\hline $\begin{array}{l}\text { Apakah anda tahu } \\
\text { fisioterapi }\end{array}$ & 100 & 20 & 80 \\
\hline $\begin{array}{l}\text { Apakah and setelah } \\
\text { lulus akan } \\
\text { melanjutkan kuliah }\end{array}$ & 100 & 90 & 10 \\
\hline $\begin{array}{l}\text { Apakah anda setelah } \\
\text { tamat bisa langsung } \\
\text { bekerja }\end{array}$ & 100 & 100 & 0 \\
\hline $\begin{array}{l}\text { Apakah anda tahu } \\
\text { dibidang } \quad \text { kesehatan } \\
\text { ada jurusan } \\
\text { fisioterapi } \\
\text { perguruan tinggi }\end{array}$ & 100 & 20 & 80 \\
\hline
\end{tabular}

Dari hasil kuisioner yang di bagikan ke siswa oleh tim pengabdian sebelum dilakukan penyuluhan didapatkan hasil data bahwa $80 \%$ siswa tidak tahu fisioterapi, $20 \%$ menyatakan tahu fisioterapi. Rata-rata siswa SMK Negeri $290 \%$ akan melanjutkan kuliah dan $10 \%$ tidak melanjutkan kuliah. Untuk pertanyaan bisa langsung bekerja setelah lulus kuliah siswa menjawab $100 \%$. Untuk pertanyaan apakah siswa tahu tentang jurusan fisioterapi sebanyak $80 \%$ siswa tidak tahu dan $20 \%$ siswa mengatakan tahu. Hal ini 
merupakan keinginan semua siswa dan orang tua kalau setelah lulus SMK anaknya dapat kuliah dan setelah kuliah dapat langsung bekerja dengan penghasilan yang memuaskan.

Penelitian sebelumnya menyatakan bahwa orang yang memiliki jenjang pendidikan yang lebih tinggi lebih mudah memahami sikap orang lain sehingga lebih menciptakan kerukunan di dalam kehidupan bermasyarakat. Pendidikan ada yang bersifat formal dan tidak formal. Pendidikan formal dilakukan melalui proses yang teratur, sistematis dan dilakukan oleh lembaga yang khusus didirikan untuk itu. Pendidikan tidak formal diperoleh lewat pengalaman dan belajar sendiri. Semestinya tingkat pendidikan formal yang lebih tinggi memberi peluang memperoleh tingkat pendapatan yang lebih tinggi (Tarigan, 2006).

\section{Penyuluhan}

Penyuluhan dilakukan selama satu jam diikuti oleh 100 siswa dibagi menjadi dua sesi, setiap sesi diikuti 50 siswa. Materi yang disampaikan berupa pengenalan fisioterapi, kasus-kasus yang dapat ditangani oleh fisioterapi, peluang kerja dan prospek dimasa mendatang. Siswa sangat antusias mengikuti pengenalan fisioterapi tersebut. Kegiatan pengenalan ini dilakukan oleh tim pengabdian diselingi dengan tanya jawab agar kegiatan tidak membosankan, memberikan doorprice bagi yang bisa menjawab pertanyaanakan diberikan hadiah oleh tim pengabdian. Di akhir kegiatan penyuluhan, tim memberikan kuisioner kembali dengan tujuan untuk melihat hasil dari apa yang telah disampaikan.

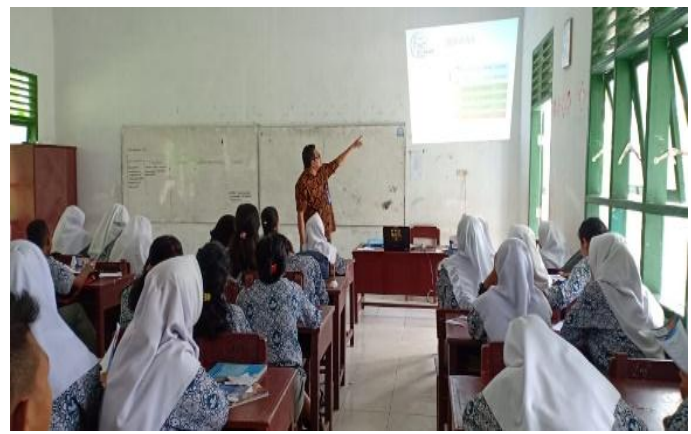

Gambar 1. Penyuluhan tentang fisioterapi sesi satu

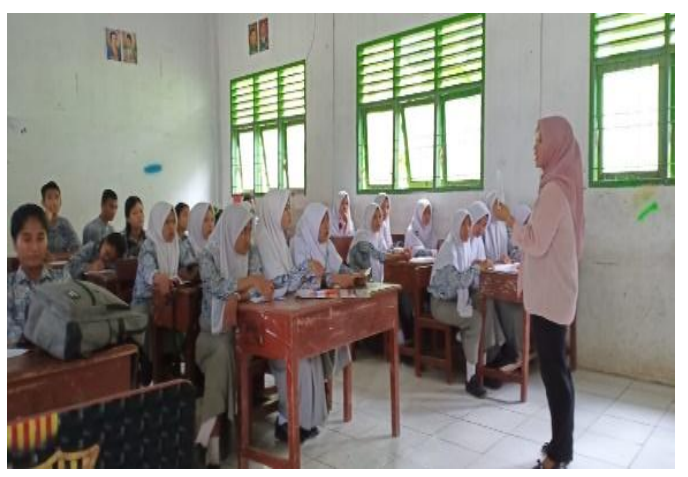

Gambar 2. Penyuluhan tentang fisioterapi sesi 2

Dari hasil kuisioner dengan pertanyaan yang berbeda dengan sebelumnya, namun masih berkaitan dengan pengetahuan siswa tentaang fisioterapi di dapatkan hasil sebagaimana Tabel 2 berikut ini.

Tabel 2. Pengetahuan siswa tentang fisioterapi setelah penyuluhan

\begin{tabular}{|l|c|c|c|}
\hline Pertanyaan & Frek & Y & $\begin{array}{l}\text { T } \\
(\%)\end{array}$ \\
\hline $\begin{array}{l}\text { Apakah anda sudah } \\
\text { paham tentang } \\
\text { fisioterapi }\end{array}$ & 100 & 85 & 15 \\
\hline $\begin{array}{l}\text { Apakah anda setelah } \\
\text { lulus akan } \\
\text { melanjutkan kuliah di } \\
\text { jurusan fisioterapi }\end{array}$ & 100 & 40 & 60 \\
\hline $\begin{array}{l}\text { Apakah harapan anda } \\
\text { setelah tamat bisa } \\
\text { langsung bekerja }\end{array}$ & 100 & 100 & 0 \\
\hline
\end{tabular}


Dari hasil tersebut di atas di dapatkan bahwa siswa yang merasa paham tentang fisioterapi sebanyak $80 \%$ dan yang belum paham sebanyak $15 \%$. Hal ini berbanding terbalik sebelum diadakan penyuluhan dimana rata-rata siswa belum paham akan fisioterapi.

Untuk pertanyaan apakah siswa akan melanjutkan kuliah ke jurusan fisioterapi, sebanyak $60 \%$ menyatakan tidak dan $40 \%$ siswa menyatakan ya, Hal ini siswa masih ragu apakah fisioterapi bisa langsung dapat bekerja, dan mereka kemungkinan juga masih perlu meminta persetujuan orang tua untuk jurusan yang kelak dipilihnya nanti dan sebagian siswa setelah tamat sekolah langusng bekerja, mengingat jurusan di SMK juga telah ditempa sedemikan rupa untuk mempunyai keahlian tertentu. Untuk pertanyaan apakah setelah tamat kuliah bisa langsung bekerja, semua responden menjawab ia atau $100 \%$. Ini memang yang diharapkan siswa dan orang tua, sehingga unutk menjawab pertanyaan ini siswa tidak ragu-ragu lagi.

Hal ini senada dinyatakan bahwa Pendidikan kejuruan diyakini memiliki konstribusi yang besar bagi perkembangan masyarakat dan peningkatan ekonomi suatu negara, daya saing negara bergantung banyak pada tenaga kerja yang memilik pengetahuan dan keterampilan, karena mereka akan meningkatkan efisiensi dan nilai tambah produksi (Hanafi, 2012). Begitu juga hasil penelitian lainnya menyatakan bahwa Pendidikan dan jenis pekerjaan berpengaruh positif dan signifikan secara parsial terhadap pendapatan seseorang (Putri, 2013)

\section{KESIMPULAN}

Berdasarakan dari hasil dan pembahasan pengabdian di SMK Negeri 2 Sibolga Kota Sibolga Provinsi Sumatera Utara dapat disimpulkan sebagai berikut :

1. Sebagian besar siswa SMK Negeri 2 Sibolga Kota Sibolga masih belum tahu tentang fisioterapi. Namun setelah diberikan penyuluhan siswa baru mengetahuinya pada saat itu juga.

2. Jurusan fisioterapi masih belum menjanjikan menurut mereka tidak bisa langsung bekerja dan jurusannya masih belum dikenal masyarakat.

3. Sebenarnya semua siswa pada dasarnya sama, ingin melanjutkan kuliah dan inging langsung mendapatkan pekerjaan sesuai harapan orang tua.

4. Perlu melakukan sosialisasi terus menerus pada siswa-siswa di Sumtera Utara khususnya siswa kelas XII agar fisioterapi dapat cepat dikenal masyarakat.

\section{REFERENCE}

Hanafi, I. (2012). Re-Orientasi Keterampilan Kerja ReOrientasi Keterampilan Kerja. Jurnal Pendidikan Vokasi, 107116.

Kemenkes RI. (2017). Profil Kesehatan Indonesia 2017. (M. K. drg.Rudy Kurniawan, Ed.). Jakarta: Kemenkes RI.

Putri, A. D. (2013). Pengaruh Umur, Pendidikan, Pekerjaan Terhadap Pendapatan Rumah 
Tangga Miskin Di Desa

Bebandem. E-Journal EP

Unud, 2(4), 173-180.

SULAIMAN, S., \& ANGGRIANI,

A. (2017). SOSIALISASI

PENCEGAHAN KASUS

STROKE PADA LANJUT

USIA DI DESA HAMPARAN

PERAK KECAMATAN.

AMALIAH: JURNAL

PENGABDIAN KEPADA

MASYARAKAT, 1(2), 17-21.

https://doi.org/10.32696/ajpkm.

v1i2.193

Sulaiman, \& Anggriani. (2018).

Efek Postur Tubuh Terhadap

Keseimbangan Lanjut Usia Di

Desa Suka Raya Kecamatan

Pancur Batu. Jurnal

JUMANTIK, 3(2), 127-140.

Retrieved from

http://jurnal.uinsu.ac.id/index.p

$\mathrm{hp} /$ kesmas/article/view/2875/17

14

Tarigan, R. (2006). Pengaruh

Tingkat Pendidikan Terhadap

Tingkat Pendapatan

Perbandingan Antara Empat

Hasil Penelitian. Jurnal

Wawasan 3, 11, 21-27. 